Title: The Uneven Perils of Unemployment and Underemployment: The Role of Employment Structure in explaining Rural-Urban Poverty Differences, 1970-2018.

Running Head: Rural-Urban Employment and Poverty

Author: Matthew M. Brooks ${ }^{1}$

1. PhD. Student; Rural Sociology and Demography

Department of Agricultural Economics, Sociology, and Education

The Pennsylvania State University. University Park, PA, 16801.

\begin{abstract}
:
There has been a persistent gap in the poverty rate between urban and rural areas of the United States, with employment composition differences likely playing a key role. Underemployment and labor force non-participation have been become significant issues in rural areas. This study uses data from the Current Population Survey for 1970 to 2018 to understand how poverty rates among 6 employment groups - (1) not in the labor force, (2) discouraged workers, (3) unemployed workers, (4) low hours workers, (5) low income workers, and (6) adequately employed workers - explain the urban-rural poverty gap. Demographic standardization and decomposition reveal that majority of the gap is explained by differences in employment-specific poverty rates. Rural individuals in all employment groups have higher poverty rates than their urban counterparts. Findings show that if rural America had either the employment structure or the employment-specific poverty rates of urban America then the poverty gap would decrease.
\end{abstract}

Keywords: Poverty, Labor Force Participation, Underemployment, Rural, Urban 


\section{RURAL-URBAN EMPLOYMENT AND POVERTY}

\section{INTRODUCTION}

News media is making constant comparisons between the so-called "two Americas"; urban America and rural America. The nightly news makes comparisons between the two concerning Donald Trump, racism, and opioids. These are all valid comparisons to make, but social scientists have long been comparing the two by asking the question "why is rural America consistently poorer than urban America?" Past studies have shown that there have historically been higher rates of poverty, childhood disadvantage, and unemployment in rural or non-metropolitan counties (Thiede and Monnat 2016; Voss et al. 2006; Weber and Miller 2017). Even after a substantial narrowing of the poverty gap in the 1960's, those who lived in non-metropolitan counties are still worse off as a whole than those who live in metropolitan counties (Weber and Miller 2017). Researches have produced many hypotheses as to why this gap exists, such as farming dependence and lower levels of education (Curtis et al. 2015; Domina 2006); but a potential explanation that is getting more scholarly traction in recent years is the differences between urban and rural work and employment structure (Slack, Thiede, and Jensen 2019). The purpose of this study is to explore why this poverty gap exists when taking into consideration urban and rural differences in employment structure and the relative poverty rates of different employment groups.

Rural researchers have known for a long time that rural work is perilous. In a 1967 report by the President's National Advisory Commission on Rural Poverty entitled The People Left Behind (1967), the notion that rural employment is precarious and does not provide the same rewards as employment in urban areas was well documented (Slack, Thiede, and Jensen 2019). Rural labor markets are significantly less diverse than urban ones (Slack 2010) and have lost many well-paying industrial jobs in recent decades (Monnat and Brown 2017). These adverse employment conditions are felt especially hard by rural Hispanics and African Americans (Crowley, Lichter, and Turner 2015; Jensen and Slack 2003).

In recent years there has also been an increased focus by researchers to understand underemployment, which is the underuse of an individual's time or skills in work, and how it relates to poverty and other forms of societal disadvantage (Mclaughlin and Coleman-jensen 2008). Rural researchers have shown that rural work in recent decades has become increasingly unstandardized and insecure, 


\section{RURAL-URBAN EMPLOYMENT AND POVERTY}

meaning that jobs with a typical "nine to five" 40 hour work week with good pay and benefits are becoming harder and harder to come by (Jensen et al. 1999; Mclaughlin and Coleman-jensen 2008). The loss of these good rural jobs have been felt disproportionately by men; with decreases in employment quality being primarily associated with loss of manufacturing jobs (Mclaughlin and Coleman-jensen 2014). Loss of these good jobs likely increases the risk of poverty for many rural households. However, there is a lack of research exploring any potential urban-rural differences in the effects that underemployment has on poverty growth or decline. Multiple studies have compared the poverty risks of urban and rural full-time workers, the unemployed, or those not in the labor force; but very few studies have compared all employment types at the same time even though all categories together contribute to the urban-rural poverty gap (McLaughlin and Perman 1991; Slack 2010; Slack, Thiede, and Jensen 2019).

In this study, I explore the differences in employment structure between rural, or nonmetro, and urban, or metro, counties. Exploring these differences highlights the relative differences in poverty rates between those in the same employment category. For example in this study I will address questions such as are the rural underemployed more likely to be in poverty than the urban underemployed? This study will answer these questions:

1. How has the employment structure and relative poverty rate of employment changed over time in metro and nonmetro counties?

2. What would nonmetro poverty look like if nonmetro counties had the employment structure and relative poverty rates of metro counties? How would these differences change over time?

3. How much of the difference between the two poverty rates is explained by differences in employment structure and relative poverty rates? How has this explained difference changed over time?

\section{MEASURING EMPLOYMENT STRUCTURE AND RELATIVE POVERTY RISK}

\section{Categorizing Employment}

Traditionally the Bureau of Labor Statistics (BLS) categorizes individuals into three employment categories: employed, unemployed, or not in the labor force-which are individuals who are not employed 


\section{RURAL-URBAN EMPLOYMENT AND POVERTY}

and not actively seeking a job. This employment scheme is commonly utilized in government reports and newspaper articles to understand the strength of the American economy. However, the Bureau of Labor Statistic's three-category scheme is limited in that it too broadly groups individuals together and does not account for two things; labor intentions and underemployment (Slack, Thiede, and Jensen 2019). One's labor intentions refers to one's desire to work, even if that individual is not actively seeking employment. In the traditional BLS scheme those who are not employed but have not actively looked for a job in the past four weeks are no longer considered unemployed and are instead deemed as not in the labor force. Underemployment in the context of this study is the condition of working but not being able to meet one's or one's family income or hourly needs. As mentioned previously, many studies of underemployment look at the mismatch between a worker's training and education and their jobs requirements; however due to data limitations rural-urban differences in underemployed by skills is not explored in this research.

To better understand the root differences in urban-rural poverty I categorize workers into the following six employment categories using an adaptation of the Labor Utilization Framework (Clogg 1979). The Labor Utilization Framework is a straightforward way of understanding how an individual's current employment situation does not match their full labor potential, both in terms of earned income and hours worked, which allows for a direct classification of underemployed (Lichter, Landry, and Clogg 1991; Slack et al. 2019). I categorize individuals as follows:

Not in the labor force individuals: Individuals who are not employed, not currently seeking employment, and do not indicate a desire to be employed.

Discouraged workers: Individuals who are not employed, would like to be employed, but are not seeking employment. Not in the labor force Individuals and Discouraged Workers together make up the Bureau of Labor Statistics" "not in the labor force" category.

Unemployed workers: Individuals who are not employed but have looked for work during the previous four weeks, or were laid-off but expect to be called back to work. This category matches the Bureau of Labor Statistics definition of unemployment 


\section{RURAL-URBAN EMPLOYMENT AND POVERTY}

Low-hours workers: Individuals who were employed less than 35 hours in the previous week; these individuals indicated they were unable to find full-time employment. This category can be considered those who are working part-time involuntarily.

Low-income workers: Individuals whose annual income (based on weekly income) is less than 125 percent of the individual's poverty threshold for that year. These individuals are working full-time or voluntarily part-time. This category can be considered the so-called working poor. Low-Hours and Low-income workers together for this study make up the larger groups of underemployed individuals. In the BLS categorization these individuals would be categorizes as employed.

Adequately employed workers: Individuals who do not fall into any other categories. These individuals are working either full time or voluntarily working part-time. Individual income is sufficient to be above 125 percent of the poverty threshold.

$\underline{\text { Data and Methods }}$

For this study, I use data taken from the Current Population Survey's (CPS) Annual Social and Economic Supplement for 1970 to 2018 . The CPS is a monthly household study conducted by the BLS and the US Census Bureau to collect information regarding America's labor, employment, and other economic issues. I extracted data via the Integrated Public Use Microdata Series (Flood et al. 2018). This study's analysis uses a sample of 3,218,012 individuals; are produces weighted estimates via the IPUMS provided ASEC individual weights. The CPS has an advantage over other data sources because it collects information regarding hours worked, employment status, employment intentions, income, and geographic information for individuals. To limit this study's analysis only prime working aged individuals, those aged 25-54, are considered. In many studies examining urban-rural comparisons, the metropolitan and nonmetropolitan classification scheme is often used as a surrogate of urban and rural areas respectively (Isserman 2005). I follow this conventional strategy and group individuals by a floating metro and nonmetro classification, meaning that individuals are grouped as nonmetro if they lived in a county that was classified as nonmetro in the year that were surveyed by the CPS; the same applies for metro individuals. 


\section{RURAL-URBAN EMPLOYMENT AND POVERTY}

I base this study's primary analysis in a comparison of nonmetro and metro employment structure and relative poverty rates. Employment structure refers to the proportion of all individuals belonging to each employment group. For example, during the 1970's 25.3 percent of nonmetro individuals were not in the labor force, .9 percent were discouraged, 3.6 percent were unemployed, 2.6 percent were low-hours, 4.0 percent were low-income, and 63.5 percent were adequately employed. The Relative poverty rate is the proportion of individuals within each employment group that are in poverty. This study uses the Official Poverty Measure, which is produced by the US Census Bureau and creates a household measure of poverty and is based on income threshold that is adjusted for household member age and composition. For example, in the 1970's 13 percent of metro not in the labor force individuals were in poverty compared to 18 percent of nonmetro not in the labor force individuals. Using these two variables, I use demographic standardization and decomposition techniques to explore the differences in metro and nonmetro poverty for 1970-2018 as well as four pooled cross-sectional comparisons for 1970-1979, 1980-1989, 1990-1999, 2000-2009, and 2010-2018.

Standardization is a useful technique in this analysis because it allows for the identification of the relative importance of the fundamental demographic rates of interest; employment structure and relative poverty rates. This study will utilize both direct and indirect standardization (Rowland 2003). In this application direct standardization will involve summing the products of multiplying nonmetro relative poverty rates by metro's employment structure for each employment group. In effect testing what nonmetro poverty would be with if nonmetro counties had metro counties' employment structure. Indirect standardization will involve summing the products of multiplying nonmetro employment structure with metro's relative poverty rates for each employment group; which addresses what the poverty rate would be if nonmetro had the relative poverty rates of metro. I will also produce results from standardizations involving the average employment structure; which will involve summing the products of multiplying both metro and nonmetro poverty rates with an averaged employment structure for each employment group.

Decomposition analysis - an extension of standardization — has the additional benefit of producing an exact percentage breakdown of how much the poverty gap between metro and nonmetro counties can be 


\section{RURAL-URBAN EMPLOYMENT AND POVERTY}

explained by differences in metro and nonmetro employment structure and relative poverty rates. Decomposition is performed by summing the products of metro employment structure multiplied by the differences between metro and nonmetro relative poverty rates for each employment group (producing the difference due to differences in relative poverty rates); summing the products of metro relative poverty rates multiplied by the differences between metro and nonmetro employment structure for each employment group (producing the difference due to differences in employment structure); and summing the product of the differences in relative poverty rates multiplied by differences in employment structure for each employment group (producing the interaction term). However due to the small size of the interaction term in each decomposition, this analysis will focus on interaction removed decomposition. I remove the interaction term by instead multiplying the relative poverty rates and employment structure by the average employment structure and average relative poverty rates, respectively. This produces the differences in the poverty gap due to differences in relative poverty rates and differences in employment structure respectively. Formulas are provided in mathematical notation in the appendix.

\section{RESULTS}

How has the employment structure and relative poverty rates of employment changes over time in metro and nonmetro places?

Since 1970, the poverty level of the prime working age population has risen for both metro and nonmetro population, with rates rising by 4.8 percentage points and 3.8 percentage points, respectively (Figure 1). Throughout the study period, nonmetro poverty is consistently higher-on average 3.2 percentage points higher. The difference between the two is the greatest in the 1980's (3.8 percentage points) and is at its smallest in 2000's (2.6 percentage points).

When comparing the changes in employment structure between metro and nonmetro at first glance, there appear to be more similarities than differences. Historically, for both metro and nonmetro counties adequately employed workers make up the vast majority of all individuals, with this group never dropping below 60 percent for either group of counties. As shown in figures $2 \mathrm{a}$ and $2 \mathrm{~b}$, the next largest group is not in the labor force individuals; however, this group for both metro and nonmetro has experienced a decline 
Figure 1. Estimates of prime worked aged poverty by metropolitan status, 1970-2018

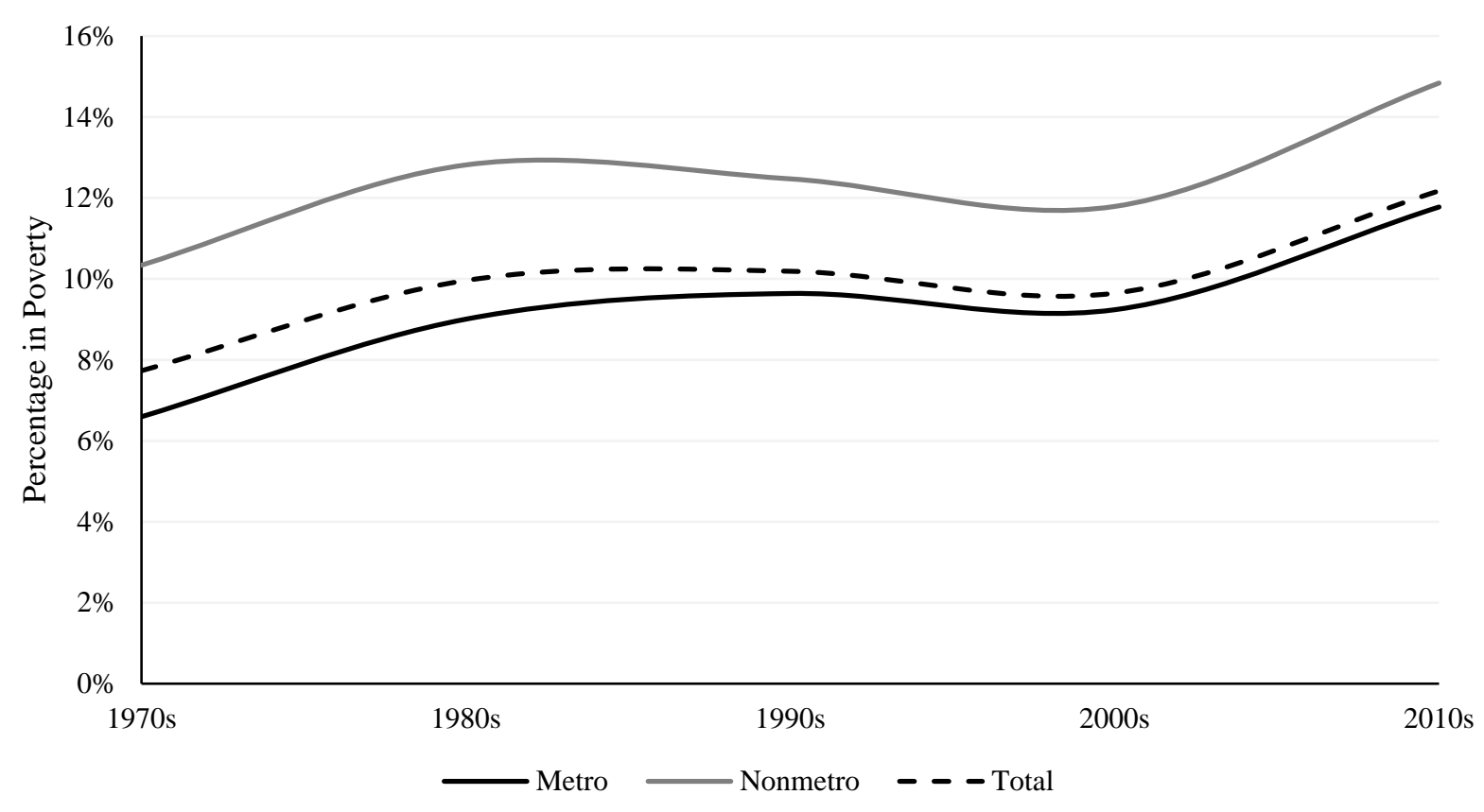

in size since the 1970's. However, in all periods, nonmetro individuals are more likely to be not in the labor force than metro individuals are. Two factors may explain these trends in the not in the labor force proportion. First, the study period coincides with rising levels of labor force participation for women; i.e., women leaving the home and taking on jobs (Toossi and Morisi 2017). Second, for men, there has been a decline in labor force participation, particularly for white former blue-collar workers. This decline is rooted in the loss of traditional masculine jobs - particularly in rural areas — as well as declining health and rising disability (Jensen and Jensen 2011), and deindustrialization of the economy (Thiede, Kim, and Valasik 2018; Thiede and Monnat 2016). In this analysis, these men would be joining the discouraged worker group or those who want to work but are not actively seeking jobs. For both populations, there has been a rise in both low hours and low wage workers; with a 1.2 point and 1.8 point increase respectively for metro individuals and a .5 and .5 point increase respectively for nonmetro.

It should be noted that this study's unique employment groups - discouraged, low hours, and low wage workers - as well as the traditional defined unemployed workers all, make up very small proportions of the total population. In all periods, these groups combined never make more than 20 percent of the total 


\section{RURAL-URBAN EMPLOYMENT AND POVERTY}

Figure 2. Distribution of prime working aged population by employment group, 1970-2018

A) Metropolitan population

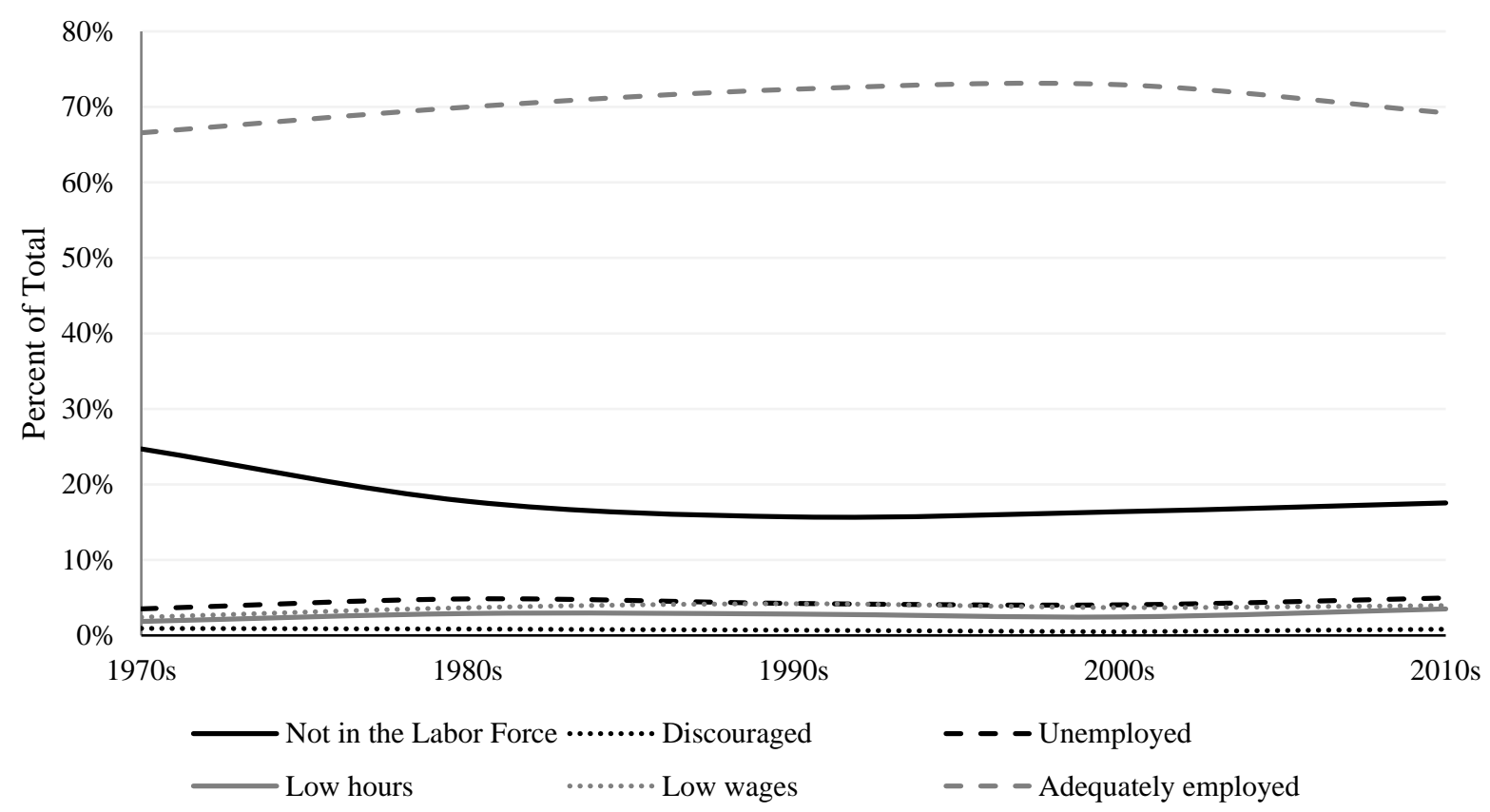

B) Nonmetropolitan population

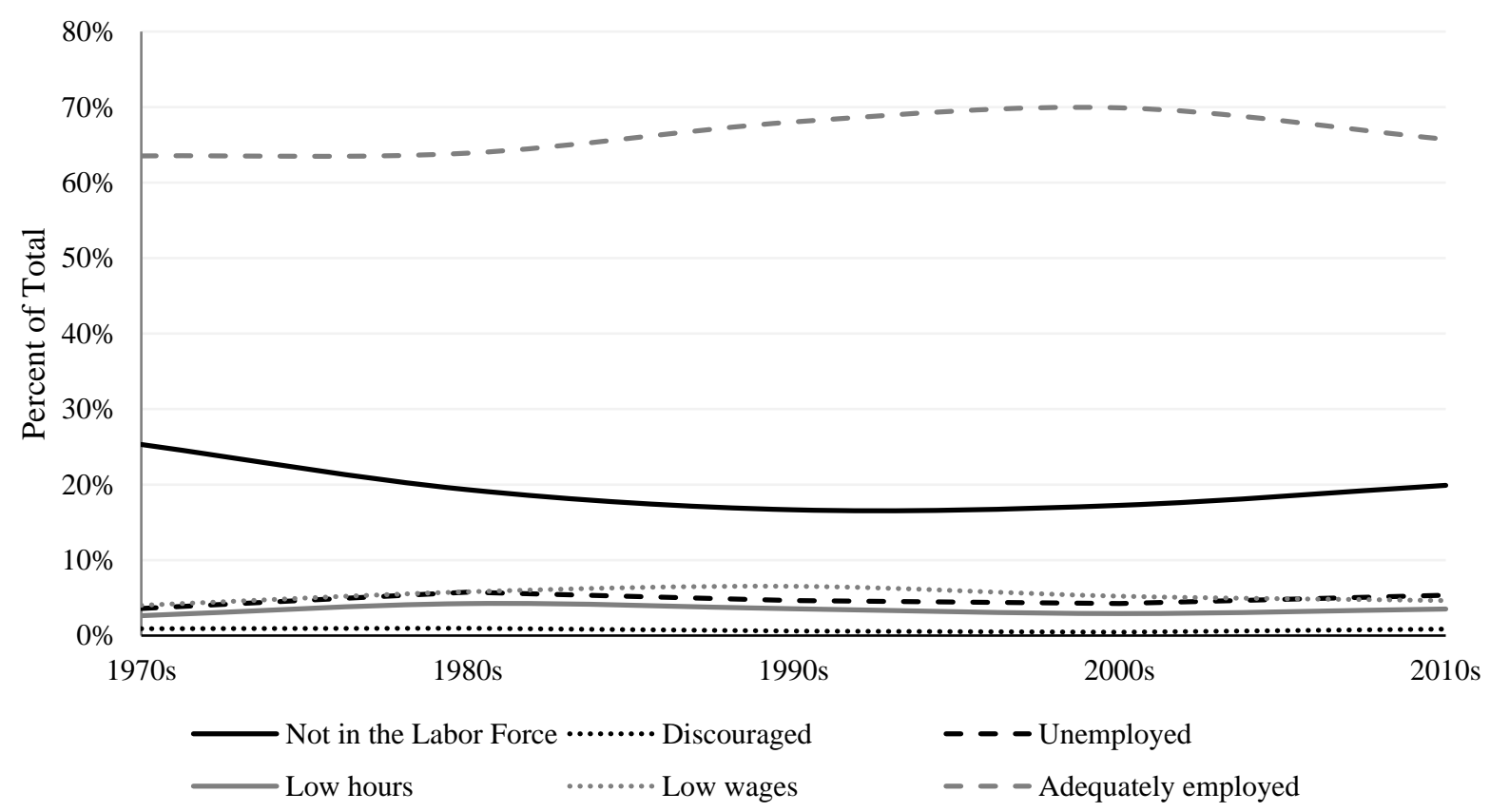


Figure 3. Estimates of relative poverty rate by employment group, 1970-2015

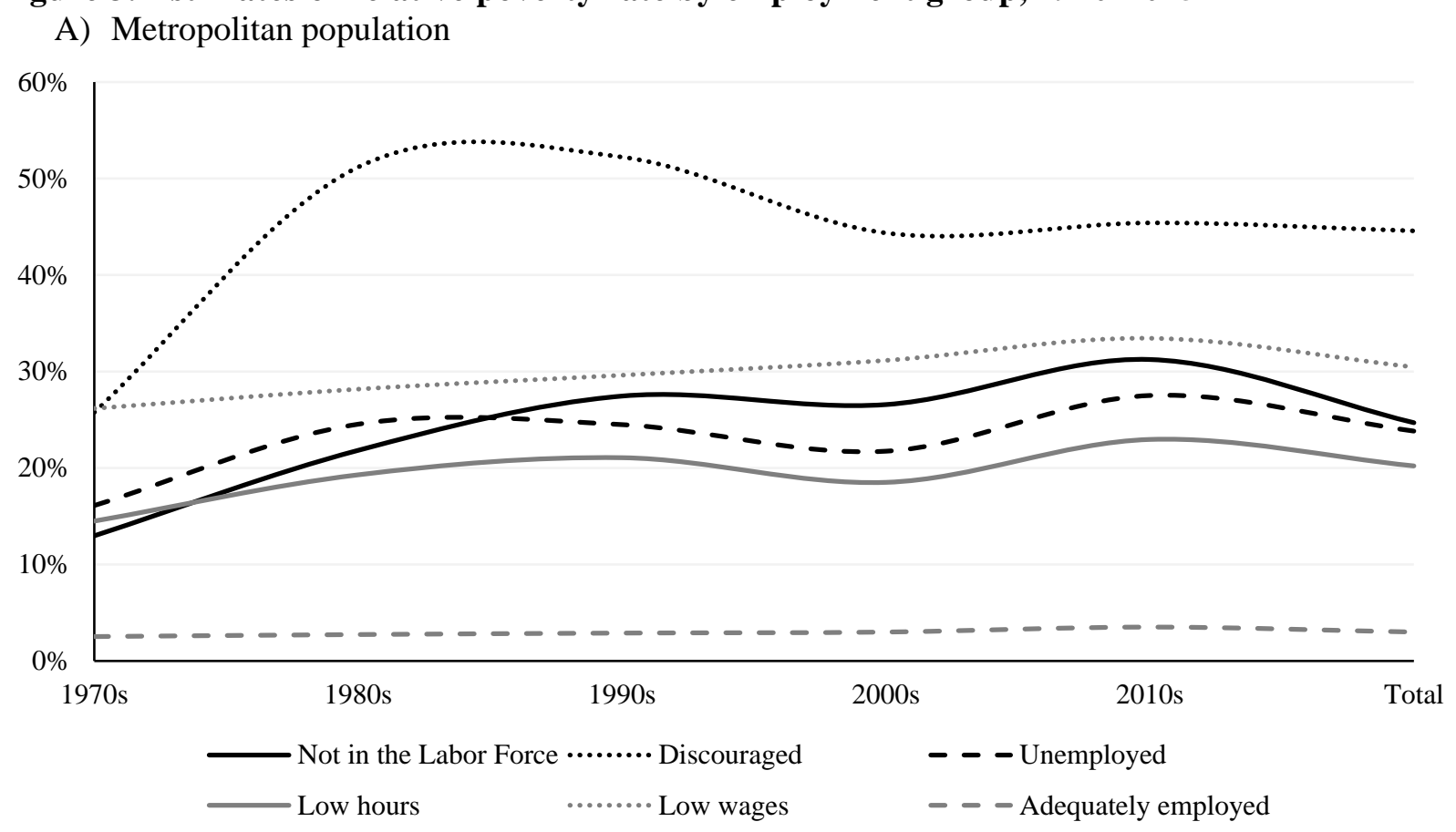

B) Nonmetropolitan population

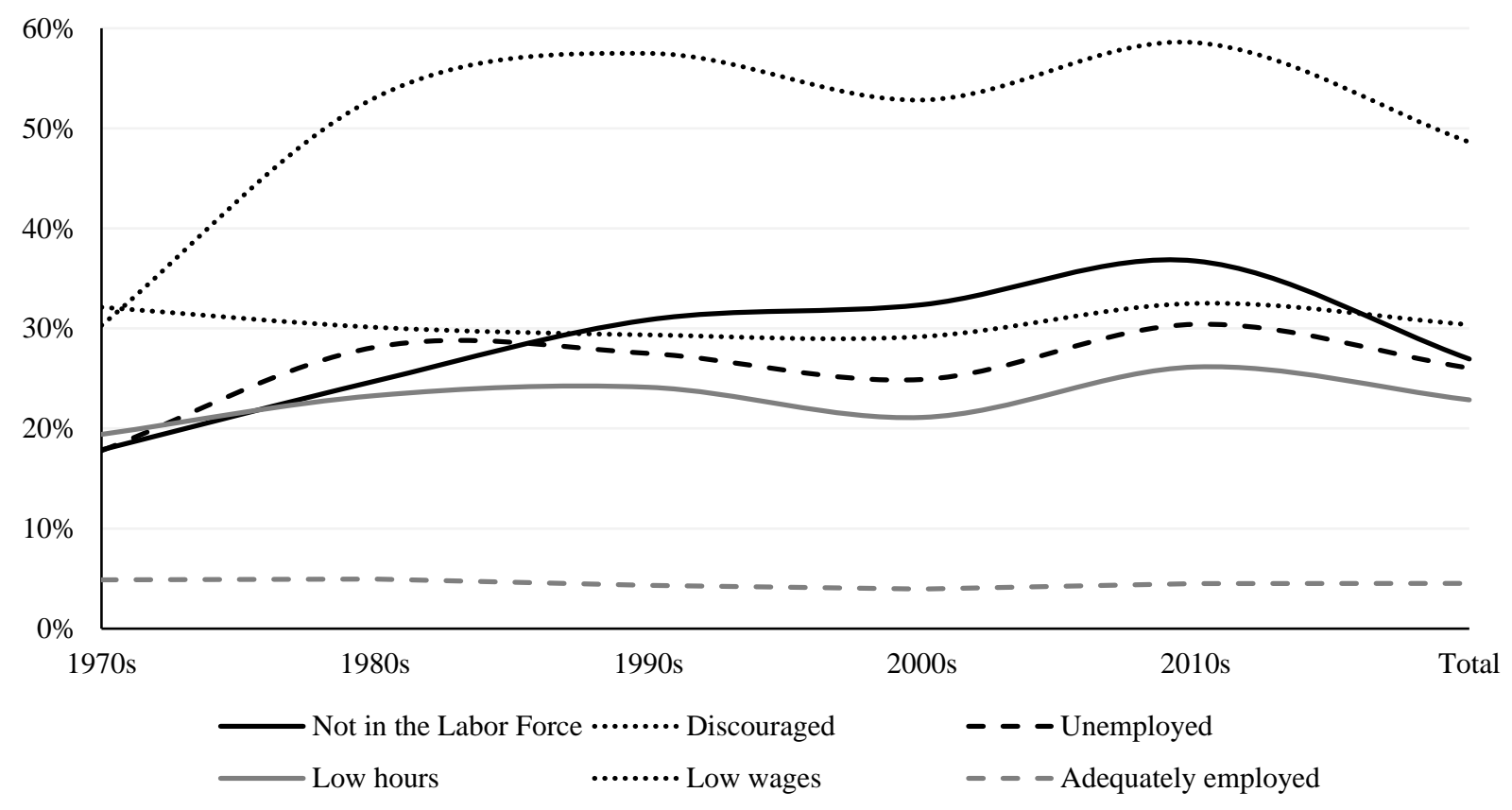




\section{RURAL-URBAN EMPLOYMENT AND POVERTY}

population for either metro or nonmetro. However, in all periods, these four groups combined make up a more substantial proportion of the employment structure for nonmetro counties.

There has also been a noticeable longitudinal change in the relative poverty rates for both metro and nonmetro areas. Overall, there is a shared consistent stratification of relative poverty rates for both populations (Figures 3a and 3b, and Table A1 [appendix]). Not surprisingly adequately employed individuals for both metro and nonmetro, have the lowest relative poverty rate, which is also consistently low throughout the period. The employment group with the highest relative poverty rate for both metro and nonmetro are discouraged workers, with relative poverty rates being over 25 percent for all decades. This may be because these individuals are not working, therefore they lack income, but since they would still prefer to work they are likely not retired individuals or they are individuals with limited savings that would make being not employed an unideal financial situation. Discouraged workers also experienced a significant rise in their relative poverty rate during the study period.

On average for all employment groups the relative poverty rates is higher for nonmetro individuals. This difference is largest for not in the labor force individuals, discouraged workers, and low hours workers. There are two periods where low wage workers had higher relative poverty rates in urban areas, however the general trend reveals a rural disadvantage. Although adequately employed workers have the lowest relative poverty rates amongst employment groups in both populations, there is still a higher relative poverty rate for rural workers. This is interesting in that even for the most secure type of employment there is a rural disadvantage.

What would nonmetro poverty look like if nonmetro counties had the employment structure and relative poverty rates of metro counties?

As established earlier, there is a gap in the total poverty rate in every decade with nonmetro always having higher levels of poverty. From 1970-1979 this gap was 3.7 percent. Using demographic standardization techniques (Table 1), I show that if nonmetro counties had the same employment structure as metro counties, the poverty rate would decrease by .4 percentage points to 9.9 percent. Furthermore, if nonmetro counties had the relative poverty rates for each employment group of metro counties, the difference would 


\section{RURAL-URBAN EMPLOYMENT AND POVERTY}

Table 1. Standardization and decomposition of metro and nonmetro poverty rates

\begin{tabular}{|c|c|c|}
\hline \multicolumn{3}{|c|}{1970 's } \\
\hline & Metro & Nonmetro \\
\hline Total Poverty Rate & $6.72 \%$ & $10.53 \%$ \\
\hline Difference & $3.81 \%$ & \\
\hline \multicolumn{3}{|l|}{ Standardization } \\
\hline$\overline{\text { Nonmetro poverty (direct standardization) }}$ & $9.89 \%$ & \\
\hline Nonmetro poverty (indirect standardization) & $7.27 \%$ & \\
\hline Metro poverty (average employment structure) & $6.99 \%$ & \\
\hline Nonmetro poverty (average employment structure) & $10.21 \%$ & \\
\hline \multicolumn{3}{|l|}{ Decomposition } \\
\hline & Difference & Percent of total difference \\
\hline Due to difference in relative poverty rates & $3.17 \%$ & $83.10 \%$ \\
\hline Due to difference in employment structure & $0.55 \%$ & $14.44 \%$ \\
\hline \multirow[t]{2}{*}{ Due to interaction } & $0.09 \%$ & $2.46 \%$ \\
\hline & Without Interaction & \\
\hline Due to difference in relative poverty rates & $3.22 \%$ & $84.33 \%$ \\
\hline Due to difference in employment structure & $0.60 \%$ & $15.67 \%$ \\
\hline \multicolumn{3}{|l|}{ ( } \\
\hline & Metro & Nonmetro \\
\hline Total Poverty Rate & $9.22 \%$ & $13.12 \%$ \\
\hline Difference & $3.90 \%$ & \\
\hline \multicolumn{3}{|l|}{ Standardization } \\
\hline$\overline{\text { Nonmetro poverty (direct standardization) }}$ & $11.72 \%$ & \\
\hline Nonmetro poverty (indirect standardization) & $10.58 \%$ & \\
\hline Metro poverty (average employment structure) & $9.90 \%$ & \\
\hline Nonmetro poverty (average employment structure) & $12.42 \%$ & \\
\hline
\end{tabular}

Decomposition

Due to difference in relative poverty rates

Difference $\quad \underline{\text { Percent of total difference }}$

Due to difference in employment structure

Due to interaction

$2.50 \% \quad 65.62 \%$

$1.36 \% \quad 35.54 \%$

$0.04 \% \quad 1.10 \%$

Due to difference in relative poverty rates

Without Interaction

Due to difference in employment structure

$2.52 \%$

$64.71 \%$

$1.38 \%$

$35.29 \%$

1990’s

Total Poverty Rate

$\underline{\text { Metro }}$

$9.94 \%$

$2.92 \%$

Difference

$11.81 \%$

Nonmetro poverty (direct standardization)

$11.01 \%$

Nonmetro poverty (indirect standardization)

$10.48 \%$

Metro poverty (average employment structure)

$12.34 \%$

$\underline{\text { Decomposition }}$

Due to difference in relative poverty rates

Due to difference in employment structure

Due to interaction

$\underline{\text { Difference }}$

$1.86 \%$

$\underline{\text { Percent of total difference }}$

$1.06 \%$

$63.83 \%$

$-0.01 \%$

$36.37 \%$

Without Interaction

$-0.20 \%$

Due to difference in relative poverty rates

$1.86 \%$

$63.73 \%$

Due to difference in employment structure

$1.06 \%$

$36.27 \%$ 


\section{RURAL-URBAN EMPLOYMENT AND POVERTY}

Table 1 (Cont.)

\begin{tabular}{|c|c|c|}
\hline \multicolumn{3}{|c|}{ 2000's } \\
\hline & Metro & Nonmetro \\
\hline Total Poverty Rate & $9.01 \%$ & $11.50 \%$ \\
\hline Difference & $2.49 \%$ & \\
\hline \multicolumn{3}{|l|}{ Standardization } \\
\hline Nonmetro poverty (direct standardization) & $10.78 \%$ & \\
\hline Nonmetro poverty (indirect standardization) & $9.72 \%$ & \\
\hline Metro poverty (average employment structure) & $9.37 \%$ & \\
\hline Nonmetro poverty (average employment structure) & $11.14 \%$ & \\
\hline \multicolumn{3}{|l|}{ Decomposition } \\
\hline & Difference & Percent of total difference \\
\hline Due to difference in relative poverty rates & $1.77 \%$ & $70.97 \%$ \\
\hline Due to difference in employment structure & $0.72 \%$ & $28.75 \%$ \\
\hline \multirow[t]{2}{*}{ Due to interaction } & $0.01 \%$ & $0.28 \%$ \\
\hline & Without Interaction & \\
\hline Due to difference in relative poverty rates & $1.77 \%$ & $71.11 \%$ \\
\hline Due to difference in employment structure & $0.72 \%$ & $28.89 \%$ \\
\hline \multicolumn{3}{|l|}{ 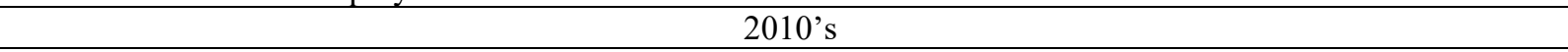 } \\
\hline & Metro & Nonmetro \\
\hline Total Poverty Rate & $11.54 \%$ & $14.54 \%$ \\
\hline Difference & $3.00 \%$ & \\
\hline \multicolumn{3}{|l|}{ Standardization } \\
\hline Nonmetro poverty (direct standardization) & $13.49 \%$ & \\
\hline Nonmetro poverty (indirect standardization) & $12.50 \%$ & \\
\hline Metro poverty (average employment structure) & $12.02 \%$ & \\
\hline Nonmetro poverty (average employment structure) & $14.01 \%$ & \\
\hline
\end{tabular}

Decomposition

Due to difference in relative poverty rates

Due to difference in employment structure

Difference

Percent of total difference

$1.94 \% \quad 64.70 \%$

$0.95 \% \quad 31.79 \%$

Due to interaction

$0.11 \% \quad 3.51 \%$

Due to difference in relative poverty rates

Without Interaction

Due to difference in employment structure

$1.99 \%$

$66.46 \%$

$1.01 \%$ $33.54 \%$

1970-2018

Total Poverty Rate

Metro

$9.56 \%$

Nonmetro

$2.72 \%$

Difference

$11.24 \%$

Nonmetro poverty (direct standardization)

$10.60 \%$

Nonmetro poverty (indirect standardization)

$10.08 \%$

Metro poverty (average employment structure)

$11.76 \%$

$\underline{\text { Decomposition }}$

Due to difference in relative poverty rates

Due to difference in employment structure

Due to interaction

Due to difference in relative poverty rates

Due to difference in employment structure

\begin{tabular}{rr} 
Difference & Percent of total difference \\
\cline { 2 - 2 } $1.68 \%$ & $61.69 \%$ \\
$1.04 \%$ & $38.36 \%$ \\
$-0.001 \%$ & $-0.05 \%$ \\
thout Interaction & \\
\hline $1.68 \%$ & $61.67 \%$ \\
$1.04 \%$ & $38.33 \%$ \\
\hline
\end{tabular}




\section{RURAL-URBAN EMPLOYMENT AND POVERTY}

decrease by 3.3 percent. Looking at the differences in these poverty rates, the rate of poverty is higher for all employment groups for nonmetro individuals. A final standardization shows that if both populations shared a similar average employment structure metro poverty would increase to 7 percent while nonmetro poverty would decrease to 10.2 percent.

When looking at other decades, similar results are present. In the 1980's - the decade with the most significant difference in metro and nonmetro poverty—nonmetro poverty would decrease by 1.4 percent if nonmetro counties had the employment structure of its urban counterpart, and if it had the relative poverty rates of metro counties, the poverty rate would decrease by 2.6 percent. In the 2000 's, the smallest gap decade, once again nonmetro poverty would decrease by a more considerable amount if the two population had a shared relative poverty rates. For the entire study period, there is a poverty gap of 2.7 percent however, that gap would decrease to 1.7 percent if nonmetro counties had metro employment structure and the gap would decrease to 1.0 percent if nonmetro relative poverty rates were replaced with metro relative poverty rates.

How much of the difference between the two poverty rates is explained by differences in employment $\underline{\text { structure and relative poverty rate? }}$

I have shown what nonmetro and metro poverty would theoretically look like if they had each other's employment structure and relative poverty rates, now I will examine how much these differences in rates contribute to the total poverty gap. Examining the individual differences in relative poverty rates shows that for every employment type the rate of being in poverty is higher in rural areas. This constant higher rate is true across decades; however, there is one expectation, in the 2000's being a low wage worker in metropolitan counties had a higher associated poverty rate. Overall, the exact differences in relative poverty rate vary across time, but the main takeaway is that these rates are usually higher. Even in the most protected group, those who are adequately employed, there is a higher chance of poverty in rural areas. Using decomposition techniques provides a percentage breakdown in how much of the total difference in poverty can be attributed to metro and nonmetro differences in employment structure and relative poverty rates. 


\section{RURAL-URBAN EMPLOYMENT AND POVERTY}

In the 1970 's, 84.7 percent of the difference in poverty can be explained by differences in relative poverty rate, compared to just 15.7 percent for differences in employment structure. In the 1980's, significantly less of the difference is due to relative poverty rate, 64.7 percent, and the role of differences in employment structure has increased to 35.3 percent. These percentages remain relatively unchanged into the 1990's. The 2000's see an increase in the poverty gap explained by the relative poverty rates, 71.1 percent; however, there is once again a decline in the 2010's when the two percentages are 61.8 percent for relative poverty rate and 38.3 percent for employment structure. For the entire period, 61.7 percent of the poverty gap is attributed to differences in relative poverty rate, compared to 38.3 percent for differences in employment structure.

Despite the fluctuating nature of these explained differences, the difference in the poverty gap explained by differences in relative poverty rates is always significantly higher. Overall, this again indicates that all employment types have higher poverty rates in nonmetro areas and the actual differences in the proportion of the population not in the labor force or are underemployment is not as important in explaining the poverty gap as earlier studies may have suggested.

\section{POLICY RECOMMENDATIONS AND SUMMARY}

Poverty is consistently higher in rural areas, and regardless of employment status, those in nonmetropolitan counties are at higher rate of being in poverty than their metro counterparts. This study shows the continuation of many of the 50-year old findings of The People Left Behind. Simply put, this study shows that the vast majority of the urban-rural poverty gap over time is due to differences in relative poverty rates. Indicating that, overall, all forms of employment carry higher chances of poverty in rural America. The findings presented in this study have significant policy implications.

Much of the welfare reform of the 1990's, was designed to get poor people supposedly back to work. The introduced welfare programs of TANF (Temporary Assistance for Needy Families) and the EITC (Earned Income Tax Credit) incentivized full-time employment through strict work requirements (Edin and Shaefer 2015). However one of the main criticisms of these programs is that the impoverished individuals and families in rural areas were already employed and that welfare programs requiring work have had little 


\section{RURAL-URBAN EMPLOYMENT AND POVERTY}

effect in improving the lives of the rural poor (Jensen and Ely 2017). As shown in this study, there is less than expected differences in employment structure between metro and nonmetro areas and that nonmetro individuals are disadvantaged at every step. To prove further this point in every decade roughly equal proportions of individuals who are adequately employed, but the poverty gap persists. Therefore, one may suggest that there is no need to implement policies designed in assisting nonmetro individuals to work because even if individuals come back to the labor force or find better employment, they are still more likely to be in poverty even if part of the adequately employed category. To put it bluntly, having a fulltime job may not be enough in rural areas. Future policies should look to help supplement the income and benefits - such as health insurance - of all workers, both full time and part time, and those that are unemployed.

The findings of this study would also suggest that underemployment is a severe issue for nonmetropolitan individuals. In every decade low hours and low wage work is more common in nonmetro counties than in metro counties. Furthermore, these rural underemployed individuals in all decades also have higher relative poverty rates. Something needs to be done to help these underemployed workers, and two policies stand out as likely solutions. First, job training programs are far less common in nonmetro areas, which in theory would help better train workers and provide them with the skills that will help them secure a higher paying full-time job (Lichter and Brown 2011; Lichter, Cornwell, and Eggebeen 1993). These programs at all levels of government should either be enacted, further funded, or potentially reevaluated to make sure that the taught skills can help find low wage workers find adequate employment in today's ever-changing economy. Second, to help those that are low hours, local governments should invest in affordable childcare services. Many low hours individuals work part-time involuntarily because working 40 hours a week would mean having to find child care for their children which is often expensive and these costs may negate the increased income of full-time work (Liu 2013; Powell 1997). Providing affordable child-care would have the dual effect of helping those who want to work full time do so and would help keep more dollars in the wallets of many impoverished working families. These programs addressing underemployment need not be limited to rural areas alone. This study also shows that 


\section{RURAL-URBAN EMPLOYMENT AND POVERTY}

underemployment is a growing problem in urban areas as well and therefore similar working poor friendly policies need to be enacted by federal, state, and local governments.

Two key limitations should be addressed by future research on this topic. First, this study relayed on pooled cross-sectional data. These ten-year periods are broad and likely mute findings that are more specific and key differences between urban and rural places. Second the focus of this analysis was on individual prime aged working adults, a group that in the life course are the least likely to be in poverty (Sandoval, Rank, and Hirschl 2009). Poverty and the decisions that shape a person's employment status are not isolated to individuals and are likely better understood and measured using household data and analysis. A natural extension of this study would be understanding how differences in household employment— the employment statuses of all members-influence poverty differently across the urban and rural continuum. A last limitation is that poverty is not solely rooted in employment; factors such as race, gender, and education also play important roles. Future studies should utilize multiple decomposition techniques to understand how multiple different types of population composition influence the poverty gap.

Two further research questions should be explored by future research. Fist, this study's utilized employment scheme should be expanded to include underemployment by skills. Understanding if there are differences in the levels of mismatch between worker's human capital and their job; which will add an additional dimension to our understanding of underemployment. Second, in addition to rural-urban comparisons further research should also account for regional differences. Poverty in America has substantial regional variations, with places like the south being especially disadvantaged (Weber and Miller 2017). Overall, this study has shown that the source of the rural-urban poverty gap is the difference in the relative poverty rates for each employment group. These uneven perils of work need to be studied further, but I believe that evidence provided by this study is a substantial first step in helping to refocus policy to aid the working poor in poor urban and rural settings. 


\section{RURAL-URBAN EMPLOYMENT AND POVERTY}

\section{REFERNCES}

Clogg, Clifford C. 1979. Measuring Underemployment: Demographic Indicators for the United States. New York, NY: Academic Press.

Crowley, Martha, Daniel T. Lichter, and Richard N. Turner. 2015. "Diverging Fortunes? Economic WellBeing of Latinos and African Americans in New Rural Destinations." Social Science Research 51:77-92.

Curtis, Katherine J., Perla E. Reyes, Heather A. O’Connell, and Jun Zhu. 2015. “Assessing the Spatial Concentration and Temporal Persistence of Poverty: Industrial Structure, Racial/Ethnic Composition, and the Complex Links to Poverty." Spatial Demography 1(2):178-94.

Domina, Thurston. 2006. "What Clean Break?: Education and Nonmetropolitan Migration Patterns, 1989-2004." Rural Sociology 71(3):373-98.

Edin, Kathryn and H. Luke Shaefer. 2015. \$2.00 a Day: Living on Almost Nothing in America. New York, NY: Houghton Mifflin Harcourt.

Isserman, Andrew M. 2005. "In the National Interest: Defining Rural and Urban Correctly in Research and Public Policy." International Regional Science Review 28(4):465-99.

Jensen, Leif and Danielle Ely. 2017. "Measures of Poverty and Implications for Portraits of Rural Hardship." Pp. 67-83 in Rural Poverty in the United States, edited by A. R. Tickamyer, J. Sherman, and J. Warlick. New York, NY: Columbia University Press.

Jensen, Leif, Jill L. Findeis, Wan-Ling Hsu, and Jason P. Schachter. 1999. "Slipping Into and Out of Underemployment: Another Disadvantage for Nonmetropolitan Workers?" Rural Sociology 64(3):417-38.

Jensen, Leif and Eric Jensen. 2011. "Employment Hardship among Rural Men.” Pp. 40-53 in Economic Restructuring and Family Well-Being in Rural America, edited by K. E. Smith and A. R. Tickamyer. University Park, PA: The Pennsylvania State University Press.

Jensen, Leif and Tim Slack. 2003. "Underemployment in America: Measurement and Evidence." American Journal of Community Psychology 32(1-2):21-31.

Lichter, Daniel T. and David L. Brown. 2011. "Rural America in an Urban Society: Changing Spatial and Social Boundaries." Annual Review of Sociology 37:565-92.

Lichter, Daniel T., Gretchen T. Cornwell, and David J. Eggebeen. 1993. "Harvesting Human Capital: Family Structure and Education Among Rural Youth." Rural Sociology 58(1):53-75.

Lichter, Daniel T., David J. Landry, and Clifford C. Clogg. 1991. "Measuring Short-Term Labor Force Mobility with the Labor Utilization Framework." Social Science Research 20(4):329-54.

Liu, Meirong. 2013. "An Ecological Review of Literature on Factors Influencing Working Mothers' Child Care Arrangements." Journal of Child and Family Studies 24(1):161-71.

Mclaughlin, Diane K. and Alisha J. Coleman-jensen. 2008. "Nonstandard Employment in the Nonmetropolitan United States *." Rural Sociology 73(4):631-59.

Mclaughlin, Diane K. and Alisha J. Coleman-jensen. 2014. "Economic Restructing and Family Structure Change, 1980 to 2000." Pp. 105-23 in Economic Restructuring and Family Well-Being in Rural America, edited by K. E. Smith and A. R. Tickamyer. University Park, PA: The Pennsylvania State University Press.

McLaughlin, Diane K. and Lauri Perman. 1991. "Returns vs. Endowments in the Earnings Attainment Process for Metropolitan and Nonmetropolitan Men and Women." Rural Sociology 56(3):339-65.

Monnat, Shannon M. and David L. Brown. 2017. "More than a Rural Revolt: Landscapes of Despair and the 2016 Presidential Election." Journal of Rural Studies 55:227-36.

President's National Advisory Committee on Rural Poverty. 1967. The People Left Behind. Washington, D.C.

Powell, Lisa M. 1997. "The Impact of Child Care Costs on the Labour Supply of Married Mothers: Evidence from Canada." The Canadian Journal of Economics 30(3):577.

Rowland, Donald T. 2003. Demographic Methods and Concepts. 1st ed. New York, NY: Oxford University Press. 


\section{RURAL-URBAN EMPLOYMENT AND POVERTY}

Sandoval, Daniel A., Mark R. Rank, and Thomas A. Hirschl. 2009. "The Increasing Risk of Poverty across the American Life Course." Demography 46(4):717-37.

Slack, Tim. 2010. "Working Poverty across the Metro-Nonmetro Divide: A Quarter Century in Perspective, 1979-2003." Rural Sociology 75(3):363-87.

Slack, Tim, Brian. C. Thiede, and Leif Jensen. (2019. Race, Residence, and Underemployment: Fifty Years in Comparative Perspective, 1968-2017. Rural Sociology, O(0), 1-41.

Thiede, Brian C. and Shannon M. Monnat. 2016. "The Great Recession and America's Geography of Unemployment." Demographic Research 35(1):891-928.

Thiede, Brian, Hyojung Kim, and Matthew Valasik. 2018. "The Spatial Concentration of America's Rural Poor Population: A Postrecession Update.” Rural Sociology 83(1):109-44.

Toossi, Mitra and Teresa L. Morisi. 2017. Women In The Workforce Before, During, And After The Great Recession.

Voss, Paul R., David D. Long, Roger B. Hammer, and Samantha Friedman. 2006. "County Child Poverty Rates in the US: A Spatial Regression Approach." Population Research and Policy Review 25(4):369-91.

Weber, Bruce and Kathleen Miller. 2017. "Poverty in Rural America Then and Now." Pp. 28-64 in Rural Poverty in the United States, edited by A. R. Tickamyer, J. Sherman, and J. Warlick. New York, NY: Columbia University Press. 


\section{RURAL-URBAN EMPLOYMENT AND POVERTY}

\section{Appendix:}

Table A1. Differences in employment structure and relative poverty rates

\begin{tabular}{|c|c|c|c|c|}
\hline \multicolumn{5}{|c|}{ 1970’s } \\
\hline & \multicolumn{2}{|c|}{ Employment structure } & \multicolumn{2}{|c|}{ Relative poverty rate } \\
\hline LUF Group & Metro & Nonmetro & Metro & Nonmetro \\
\hline Not in the Labor Force & $24.7 \%$ & $25.3 \%$ & $13.2 \%$ & $18.2 \%$ \\
\hline Discouraged & $0.9 \%$ & $0.9 \%$ & $26.2 \%$ & $30.9 \%$ \\
\hline Unemployed & $3.5 \%$ & $3.6 \%$ & $16.4 \%$ & $18.1 \%$ \\
\hline Low hours & $1.9 \%$ & $2.6 \%$ & $14.8 \%$ & $19.8 \%$ \\
\hline Low wages & $2.4 \%$ & $4.0 \%$ & $26.7 \%$ & $32.7 \%$ \\
\hline Adequately employed & $66.6 \%$ & $63.5 \%$ & $2.6 \%$ & $5.0 \%$ \\
\hline \multicolumn{5}{|c|}{ 1980’s } \\
\hline & \multicolumn{2}{|c|}{ Employment structure } & \multicolumn{2}{|c|}{$\underline{\text { Relative poverty rate }}$} \\
\hline LUF Group & Metro & Nonmetro & Metro & Nonmetro \\
\hline Not in the Labor Force & $17.8 \%$ & $19.3 \%$ & $22.4 \%$ & $25.3 \%$ \\
\hline Discouraged & $0.8 \%$ & $1.0 \%$ & $52.4 \%$ & $54.3 \%$ \\
\hline Unemployed & $4.8 \%$ & $5.8 \%$ & $25.1 \%$ & $28.8 \%$ \\
\hline Low hours & $2.9 \%$ & $4.2 \%$ & $19.8 \%$ & $23.8 \%$ \\
\hline Low wages & $3.7 \%$ & $5.8 \%$ & $28.8 \%$ & $30.8 \%$ \\
\hline Adequately employed & $70.0 \%$ & $63.9 \%$ & $2.8 \%$ & $5.1 \%$ \\
\hline \multicolumn{5}{|c|}{ 1990’s } \\
\hline & \multicolumn{2}{|c|}{ Employment structure } & \multicolumn{2}{|c|}{ Relative poverty rate } \\
\hline LUF Group & Metro & Nonmetro & Metro & Nonmetro \\
\hline Not in the Labor Force & $15.7 \%$ & $16.7 \%$ & $28.3 \%$ & $31.8 \%$ \\
\hline Discouraged & $0.7 \%$ & $0.6 \%$ & $53.9 \%$ & $59.3 \%$ \\
\hline Unemployed & $4.2 \%$ & $4.6 \%$ & $25.3 \%$ & $28.4 \%$ \\
\hline Low hours & $2.8 \%$ & $3.5 \%$ & $21.7 \%$ & $24.9 \%$ \\
\hline Low wages & $4.2 \%$ & $6.5 \%$ & $30.5 \%$ & $30.3 \%$ \\
\hline Adequately employed & $72.3 \%$ & $68.0 \%$ & $3.0 \%$ & $4.5 \%$ \\
\hline \multicolumn{5}{|c|}{ 2000's } \\
\hline & \multicolumn{2}{|c|}{ Employment structure } & \multicolumn{2}{|c|}{ Relative poverty rate } \\
\hline LUF Group & Metro & Nonmetro & Metro & Nonmetro \\
\hline Not in the Labor Force & $16.4 \%$ & $17.2 \%$ & $25.9 \%$ & $31.6 \%$ \\
\hline Discouraged & $0.5 \%$ & $0.5 \%$ & $43.3 \%$ & $51.5 \%$ \\
\hline Unemployed & $4.0 \%$ & $4.3 \%$ & $21.2 \%$ & $24.3 \%$ \\
\hline Low hours & $2.4 \%$ & $2.9 \%$ & $18.1 \%$ & $20.6 \%$ \\
\hline Low wages & $3.7 \%$ & $5.2 \%$ & $30.4 \%$ & $28.5 \%$ \\
\hline Adequately employed & $72.9 \%$ & $69.9 \%$ & $2.9 \%$ & $3.9 \%$ \\
\hline \multicolumn{5}{|c|}{2010 's } \\
\hline & \multicolumn{2}{|c|}{ Employment structure } & \multicolumn{2}{|c|}{ Relative poverty rate } \\
\hline LUF Group & Metro & Nonmetro & Metro & Nonmetro \\
\hline Not in the Labor Force & $17.6 \%$ & $19.9 \%$ & $30.6 \%$ & $36.0 \%$ \\
\hline Discouraged & $0.8 \%$ & $0.9 \%$ & $44.5 \%$ & $57.4 \%$ \\
\hline Unemployed & $5.0 \%$ & $5.3 \%$ & $27.0 \%$ & $29.8 \%$ \\
\hline Low hours & $3.5 \%$ & $3.5 \%$ & $22.5 \%$ & $25.6 \%$ \\
\hline Low wages & $4.0 \%$ & $4.6 \%$ & $32.8 \%$ & $31.9 \%$ \\
\hline Adequately employed & $69.2 \%$ & $65.7 \%$ & $3.4 \%$ & $4.4 \%$ \\
\hline \multicolumn{5}{|c|}{$1970-2018$} \\
\hline & \multicolumn{2}{|c|}{ Employment structure } & \multicolumn{2}{|c|}{ Relative poverty rate } \\
\hline LUF Group & Metro & Nonmetro & Metro & Nonmetro \\
\hline Not in the Labor Force & $17.8 \%$ & $19.8 \%$ & $24.7 \%$ & $26.9 \%$ \\
\hline Discouraged & $0.7 \%$ & $0.8 \%$ & $44.6 \%$ & $48.6 \%$ \\
\hline Unemployed & $4.4 \%$ & $4.7 \%$ & $23.8 \%$ & $26.0 \%$ \\
\hline Low hours & $2.8 \%$ & $3.4 \%$ & $20.2 \%$ & $22.9 \%$ \\
\hline Low wages & $3.7 \%$ & $5.3 \%$ & $30.5 \%$ & $30.4 \%$ \\
\hline Adequately employed & $70.6 \%$ & $66.1 \%$ & $3.0 \%$ & $4.5 \%$ \\
\hline
\end{tabular}




\section{RURAL-URBAN EMPLOYMENT AND POVERTY}

\section{Formulas}

Direct Standardization:

$$
\left.\sum_{\text {Employment Group }} \text { (realtive poverty rates } \text { NonMetro } \times \text { employment }_{\text {strucutre }} \text { Metro }\right)
$$

Indirect Standardization:

$$
\sum_{\text {Employment Group }}\left(\text { employment strucutre } \text { NonMetro } \times \text { relative poverty rates }_{\text {Metro }}\right)
$$

Standardization with Average Employment Structure:

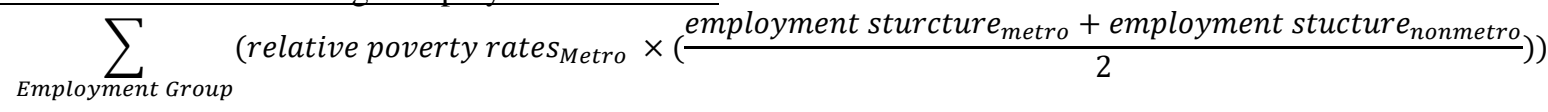

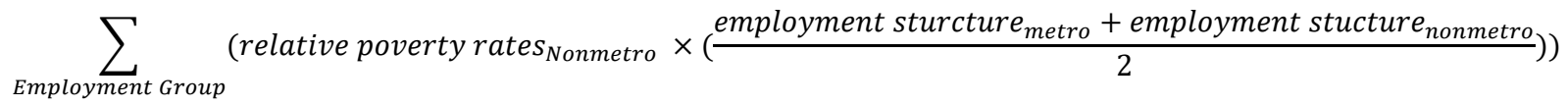

Difference due to Differences in Employment Structure:

$$
\left.\sum_{\text {Employment Group } \text { (realtive poverty rates }} \text { metro } \times\left(\text { employment } \text { strucutre }_{\text {metro }}-\text { employment }_{\text {structure }} \text { nonmetro }\right)\right)
$$

Difference due to Differences in Relative Poverty Risks:

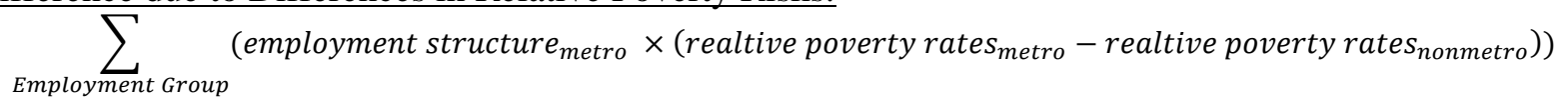

\section{Interaction Term:}

\footnotetext{
$\sum_{\text {Employment Group }}\left(\left(\right.\right.$ employment strucutre metro - employment strucutre $\left._{\text {nonmetro }}\right) \times\left(\right.$ realtive poverty rates metro $_{\text {mealtive poverty rates }}-$ renmetro $\left.\left._{\text {non }}\right)\right)$
} 